\title{
Destructive soft tissue metastases in advanced colorectal cancer: a case report
}

\author{
Michael S. Krasovitsky ${ }^{1,2,3}$, David Goldstein ${ }^{1,3} \wedge$ \\ ${ }^{1}$ Comprehensive Cancer Centre, Prince of Wales Hospital, Randwick, NSW, Australia; ${ }^{2}$ Kinghorn Cancer Centre, St Vincent's Hospital, \\ Darlinghurst, NSW, Australia; ${ }^{3}$ Prince of Wales Clinical School, Faculty of Medicine, University of New South Wales, Randwick, NSW, Australia \\ Correspondence to: Michael S. Krasovitsky. Comprehensive Cancer Centre, Prince of Wales Hospital, Barker St, Randwick, NSW, Australia. \\ Email: Michael.krasovitsky@unsw.edu.au.
}

\begin{abstract}
Extremity soft tissue metastases are a rare, but recognised complication of advanced colon cancer. There is limited data regarding their management, and such metastases are associated with a poor prognosis. The investigation of such metastases may require full-body positron emission tomography (PET) scanning, rather than per-protocol PET scanning. We present the case of a 76-year-old incarcerated male with a history of T4b N1b M0 right colon adenocarcinoma, who presented with right distal thigh pain and gross disfigurement. MRI demonstrated an erosive, verrucous soft tissue lesion, which had not been present on the diagnostic, per-protocol PET scan. Whole-body PET scan subsequently confirmed a highly avid lesion, with biopsy confirming metastatic adenocarcinoma consistent with colonic origin. The patient's pain was treated with multimodal analgesia and radiotherapy. Despite these interventions, locoregional symptoms from the extremity metastasis were difficult to control. The patient died 4 months following the diagnosis of metastatic disease. This case highlights the importance of recognising extremity soft tissue abnormalities as a possible consequence of advanced colon cancer. It illustrates the importance of whole-body PET scanning and explores management complexities that may present when caring for incarcerated patients. The subsequent literature review explores the existing literature regarding extremity soft tissue metastases in colon cancer. Further data regarding both the incidence and optimal management of such lesions is required.
\end{abstract}

Keywords: Colon cancer; nuclear medicine; positron emission tomography (PET); case report

Submitted Feb 09, 2021. Accepted for publication Jun 29, 2021.

doi: 10.21037/apm-21-362

View this article at: https://dx.doi.org/10.21037/apm-21-362

\section{Introduction}

In 2018, colorectal cancer (CRC) was both the fourth most commonly diagnosed cancer, and the third most deadly cancer in the world (1). Alongside an increasing global incidence, multimodal management of this condition has improved outcomes (2). As a result of these epidemiological shifts and therapeutic advances, the prevalence of colorectal cancer has increased, and clinicians of all disciplines require an understanding of this multifaceted malignancy.

Soft tissue metastases from colorectal cancer are a rare occurrence. Acrometastases, defined as metastases located distal to the elbow and knee (3), account for approximately $0.1 \%$ of all metastases, with metastatic colorectal carcinoma accounting for $10 \%$ of these cases (4). The prevalence of proximal extremity soft tissue metastases in colon cancer is not known. Furthermore, the optimal management and prognosis of such patients is not known.

Here, we present the case of a 76-year-old incarcerated male, who presented to hospital with a tender and grossly disfigured distal right thigh on a background of stage III

\footnotetext{
^ ORCID: Michael Samuel Krasovitsky, 0000-0001-6287-3593; David Goldstein, 0000-0001-6142-3291.
} 


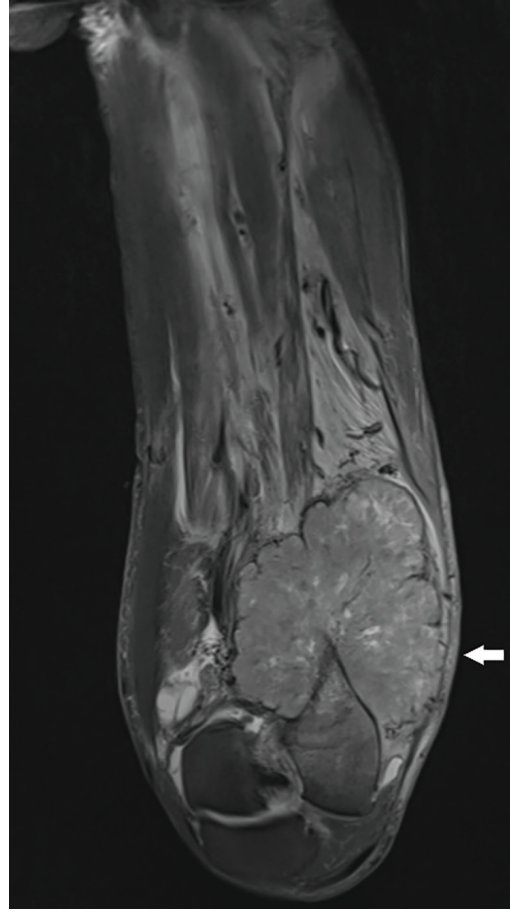

Figure 1 MRI of the distal thigh, demonstrating a verrucous, heterogenous soft tissue lesion invading locoregional structures including the femur. MRI, magnetic resonance imaging.

colorectal cancer. This case highlights both the complexity of caring for individuals within corrective services, and the importance of performing full body, rather than limited, positron emission tomography (PET) scanning in individuals suspected of advanced cancer. It also illustrates the complexities inherent in the management of extremity soft tissue metastases. We present the following article in accordance with the CARE reporting checklist (available at https://apm.amegroups.com/article/view/10.21037/apm-21$362 / \mathrm{rc})$.

\section{Case presentation}

All procedures performed in this study were in accordance with the ethical standards of the institutional and/or national research committee(s) and with the Helsinki Declaration (as revised in 2013). Written informed consent was obtained from the patient for publication of this case report and accompanying images. A copy of the written consent is available for review by the editorial office of this journal. The 76-year-old male had a history of systemic lupus erythematosus, uncomplicated common variable immunodeficiency and biventricular heart failure. Six months prior to presentation, while incarcerated, he had presented to another hospital with fatigue, and iron deficiency anaemia was detected. Colonoscopy demonstrated a $9 \mathrm{~cm}$ ascending colonic lesion, biopsy of which confirmed adenocarcinoma. Pre-operative CT staging demonstrated no metastatic disease. A preoperative PET scan, which examined the head, neck, chest, abdomen and pelvis, as per institutional policy, was negative for metastatic disease.

The patient subsequently underwent an uncomplicated right hemicolectomy, with pathology demonstrating a $120 \mathrm{~mm}$ moderately differentiated adenocarcinoma, with 2 of 14 nodes involved, indicating T4b N1b M0 disease. Immunohistochemistry demonstrated loss of MLH1 and the presence of a BRAF V600E mutation. Adjuvant chemotherapy or enrolment in a clinical trial were recommended by the multidisciplinary team. The patient was subsequently transferred to a different correctional facility, and follow-up with the medical oncology service was not undertaken. He presented to our service 4 months following surgery.

On presentation, the patient described moderate to severe pain originating from a mass on the distal anterolateral right thigh. Though the mass had been present for only two months, the patient did provide a history of worsening mobility and pain over the preceding six months (commencing prior to surgery for his colon cancer).

On examination, the patient appeared cachectic and unwell. A $100 \times 80 \mathrm{~mm}$ tender mass was noted on the anterolateral distal thigh, with marked dilatation of the superficial vasculature proximal to the mass. The knee was fixed at 15 degrees of flexion. The remainder of the examination was notable only for a left basal pleural rub.

An MRI of the distal thigh was performed (Figure 1). This demonstrated a $110 \times 76 \times 117 \mathrm{~mm}$ verrucous mass involving the anterolateral and posterior distal thigh, with invasion into bone and surrounding soft tissue, suggestive of an aggressive extremity sarcoma. A repeat PET scan was requested. On this occasion, the entire body, rather than simply the head to pelvis, was scanned. The PET demonstrated intense FDG avidity at the femoral site, with a lesional $\mathrm{SUV}_{\max }$ of 20.6. In addition, metastatic deposits were detected in the adrenal glands, left pleura and brain (Figure 2).

After extensive consultation, biopsy of the lesion was undertaken. Histopathology confirmed moderately differentiated adenocarcinoma, with diffusely positive CDX2 staining, suggesting colonic origin. The patient was 

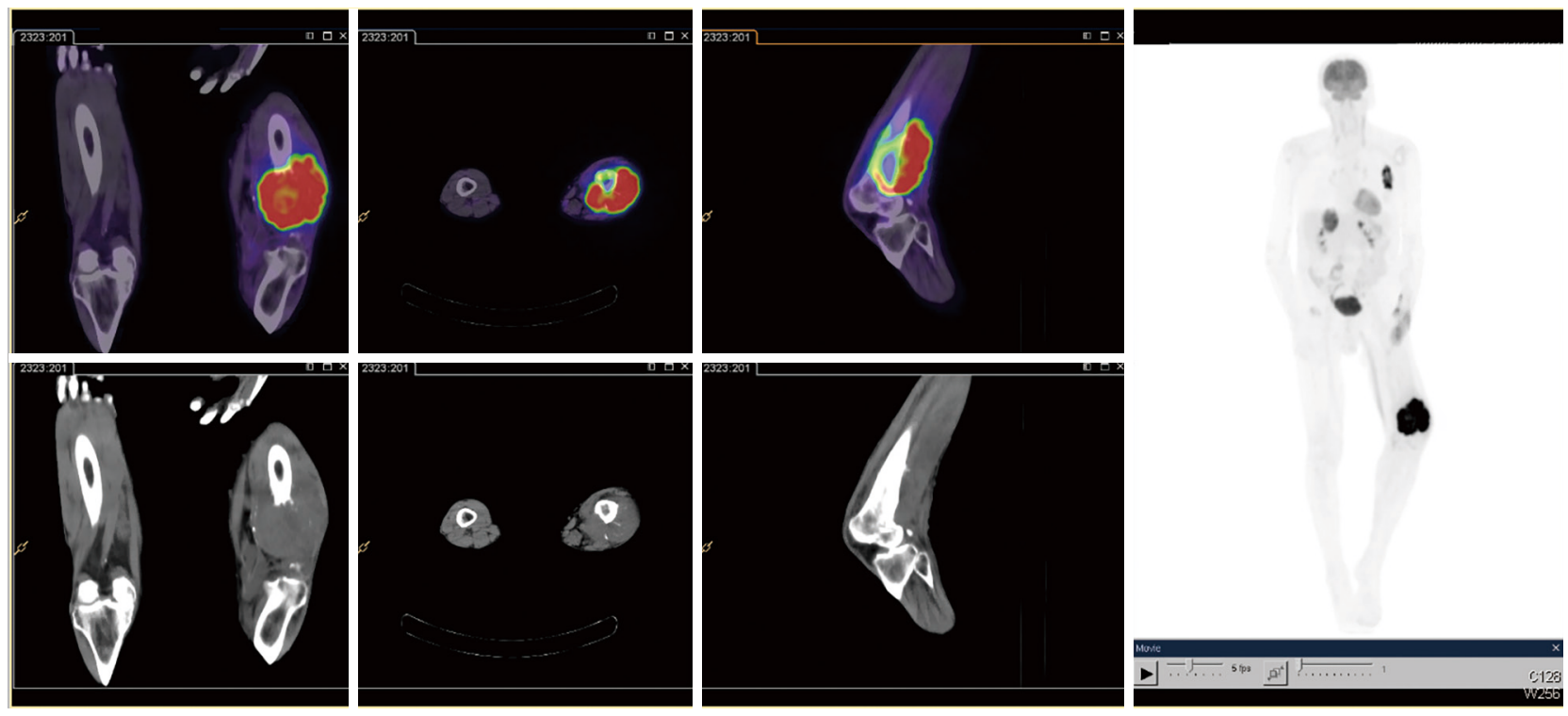

Figure 2 FDG-PET scan demonstrating an extensive soft tissue lesion surrounding the distal femur, as well as FDG avid disease in the thorax, abdomen and brain. FDG, fluoro-2-deoxy-D-glucose; PET, positron emission tomography.

diagnosed with metastatic colon carcinoma.

The patient's painful thigh lesion was treated with pharmacotherapy and palliative intent radiotherapy. Pharmacotherapy included regular subcutaneous hydromorphone, pregabalin, paracetamol, ketorolac and oral methadone. A transdermal 5\% lignocaine patch was trialled, to minimal effect. The patient was also treated with external beam radiotherapy (30 Gy in 10 fractions using a volumetric modulated arc therapy technique). One month following completion of radiotherapy, the patient's opioid requirements had reduced, and he was able to cease methadone therapy. His gait remained poor, but he was able to wait-bear on the right leg.

The patient's performance status precluded the use of cytotoxic therapy, and best supportive care was undertaken following treatment of the distal thigh metastasis. He died four months after diagnosis.

\section{Discussion}

We have presented the case of a 76-year-old gentleman who presented with a destructive soft tissue metastasis from metastatic colorectal cancer. It is hypothesized that the patient had metastatic disease at the time of his initial diagnosis, but that this was not ascertained given the limited scan sequences generated on routine, per-protocol PET. The patient had complex palliative care requirements requiring multimodal analgesia, and died soon after his diagnosis of metastatic disease.

Though uncommon, soft tissue metastases from colon cancer must always be considered in patients presenting with destructive extremity lesions, particularly in those with a history of malignancy (5-7). A number of case reports and case series have been published since the first description of acrometastases at the beginning of the twentieth century (5-20). Table 1 describes the patient characteristics and location of metastatic disease in select patients with colorectal cancer and extremity metastases. The table highlights the various metastatic sites that may be affected in colon cancer metastasizing to the extremities.

This table highlights the multiple possible manifestations of extremity metastatic disease in colon cancer. Only limited data is available regarding the optimal therapeutic approach to such lesions, with previously employed strategies including surgery, radiotherapy, systemic therapy and supportive care $(4,8,10,14)$. The poor prognostic ramifications of extremity metastases have been highlighted by the available case reports $(14,21)$.

This case also illustrates the limitations of performing FDG-PET scans that end at the lower pelvis. The presented patient had knee pain at the time of his first PET scan, and may have had metastatic disease at this point. His pre-operative PET scan, however, did not extend to the knees or lower legs, and this disease was therefore 
Table 1 Summary of case reports describing extremity metastases in individuals with advanced colon cancer

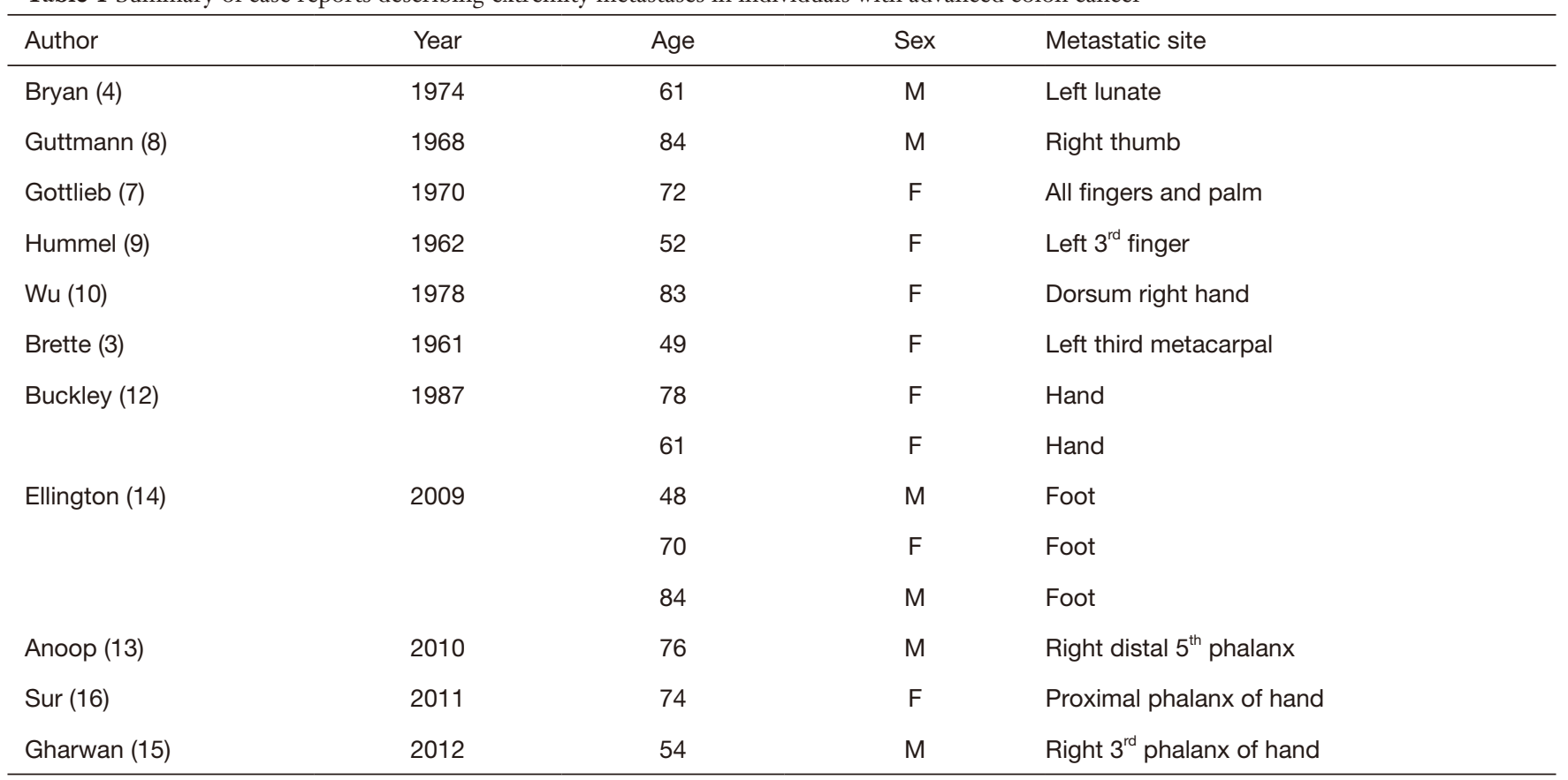

unrecognised. Whole body PET scanning is warranted in patients with confirmed malignancy, and we recommend altering institutional policy to reflect this recommendation.

Finally, this case highlights the tenuous road that many incarcerated patients are forced to travel in order to receive care. Changes in location of incarceration, institutional barriers, inadequate communication and insufficient patient empowerment can and do drastically affect the health of prisoners $(22,23)$. This population carry both a higher incidence of cancer and a worse prognosis once diagnosed (22-24). As such, it is our collective responsibility to ensure that health infrastructure adequately supports this vulnerable population.

Strengths of this case report include illustrative radiology, and the proffered review of previously published cases. Limitations include the absence of patient-reported outcomes and the lack of histopathological imagery.

This case report highlights an uncommon consequence of advanced colon cancer and illustrates the management complexity present in caring for patients with soft tissue extremity metastases. Further data regarding the incidence, prevalence and optimal management of such metastases is required.

\section{Acknowledgments}

Funding: None.

\section{Footnote}

Reporting Checklist: The authors have completed the CARE reporting checklist. Available at https://apm.amegroups. com/article/view/10.21037/apm-21-362/rc

Conflicts of Interest: Both authors have completed the ICMJE uniform disclosure form (available at https://apm. amegroups.com/article/view/10.21037/apm-21-362/coif). The authors have no conflicts of interest to declare.

Ethical Statement: The authors are accountable for all aspects of the work in ensuring that questions related to the accuracy or integrity of any part of the work are appropriately investigated and resolved. All procedures performed in this study were in accordance with the ethical standards of the institutional and/or national research committee(s) and with the Helsinki Declaration (as revised in 2013). Written informed consent was obtained from the patient for publication of this case report and accompanying 
images. A copy of the written consent is available for review by the editorial office of this journal.

Open Access Statement: This is an Open Access article distributed in accordance with the Creative Commons Attribution-NonCommercial-NoDerivs 4.0 International License (CC BY-NC-ND 4.0), which permits the noncommercial replication and distribution of the article with the strict proviso that no changes or edits are made and the original work is properly cited (including links to both the formal publication through the relevant DOI and the license). See: https://creativecommons.org/licenses/by-nc-nd/4.0/.

\section{References}

1. Bray F, Ferlay J, Soerjomataram I, et al. Global cancer statistics 2018: GLOBOCAN estimates of incidence and mortality worldwide for 36 cancers in 185 countries. CA Cancer J Clin 2018;68:394-424.

2. Brouwer NPM, Bos ACRK, Lemmens VEPP, et al. An overview of 25 years of incidence, treatment and outcome of colorectal cancer patients. Int J Cancer 2018;143:2758-66.

3. Brette M, Grandmottet P, Tissot A. Métastase métacarpienne isolée d'un épithélioma colique. Lyon Méd 1961;205:733-9.

4. Bryan RS, Soule EH, Dobyns JH, et al. Metastatic lesions of the hand and forearm. Clin Orthop Relat Res 1974;(101):167-70.

5. Hasegawa S, Sakurai Y, Imazu H, et al. Metastasis to the forearm skeletal muscle from an adenocarcinoma of the colon: report of a case. Surg Today 2000;30:1118-23.

6. Hlavatá Z, Pazderová N, Povinec $\mathrm{P}$, et al. The value of 18-FDG PET/CT imaging in a patient with atypical metastatic colorectal cancer--case report: 18-FDG PET/ CT in colorectal cancer. Klin Onkol 2009;22:284-7.

7. Stomeo D, Tulli A, Ziranu A, et al. Acrometastasis: a literature review. Eur Rev Med Pharmacol Sci 2015;19:2906-15.

8. Gottlieb JA, Schermer DR. Cutaneous metastases from carcinoma of the colon. JAMA 1970;213:2083.

9. Guttmann G, Stein I. Metastatic tumor of the thumb from adenocarcinoma of the colon. Int Surg 1968;49:217-21.

10. HUMMEL J, SCOTT RM. Adenocarcinoma of the rectum with metastases to a phalanx; a case report. J Ky Med Assoc 1962;60:158-9.

11. Wu KK, Guise ER. Metastatic tumors of the hand: a report of six cases. J Hand Surg Am 1978;3:271-6.

12. Kerin R. Metastatic tumors of the hand. A review of the literature. J Bone Joint Surg Am 1983;65:1331-5.

13. Buckley N, Peebles Brown DA. Metastatic tumors in the hand from adenocarcinoma of the colon. Dis Colon Rectum 1987;30:141-3.

14. Anoop TM, George S, Divya KP, et al. Metastatic phalangeal osteolysis as an initial presentation of carcinoma colon. Am J Surg 2010;200:e61-3.

15. Ellington JK, Kneisl JS. Acrometastasis to the foot: three case reports with primary colon cancer. Foot Ankle Spec 2009;2:140-5.

16. Gharwan H, Yarlagadda L, Duffy A. Acrometastasis as the Initial Presentation of a KRAS-Positive Colon Cancer. Case Rep Oncol 2012;5:404-8.

17. Sur YJ, Kang YK, Bahk WJ, et al. Metastatic malignant tumour in the hand. J Plast Surg Hand Surg 2011;45:90-5.

18. Francis KC. Tumors and infections of the foot. In: Gianestras NJ. editor. Foot Disorders: Medical and Surgical Management. Edition 1. Philadelphia: Lea \& Febiger, 1967:452-81.

19. Gall RJ, Sim FH, Pritchard DJ. Metastatic tumors to the bones of the foot. Cancer 1976;37:1492-95.

20. Härkönen M, Olin PE. Rectal carcinoma metastasizing to a toe. Acta Med Scand 1980;207:235-6.

21. Ihle PM, McBeath AA. Bone metastasis from colonic carcinoma. A case report. J Bone Joint Surg Am 1973;55:398-400.

22. Binswanger IA, Krueger PM, Steiner JF. Prevalence of chronic medical conditions among jail and prison inmates in the USA compared with the general population. J Epidemiol Community Health 2009;63:912-9.

23. Mathew P, Elting L, Cooksley C, et al. Cancer in an incarcerated population. Cancer 2005;104:2197-204.

24. Kouyoumdjian FG, Pivnick L, McIsaac KE, et al. Cancer prevalence, incidence and mortality in people who experience incarceration in Ontario, Canada: A population-based retrospective cohort study. PLoS One 2017;12:e0171131.

Cite this article as: Krasovitsky MS, Goldstein D. Destructive soft tissue metastases in advanced colorectal cancer: a case report. Ann Palliat Med 2022;11(6):2170-2174. doi: 10.21037/apm21-362 